\title{
GREGORIO MAGNO Y LOS ERUDITOS PROTESTANTES EN LOS PRIMEROS 50 AÑOS DE LA REFORMA*
}

\author{
GREGORY THE GREAT AND THE PROTESTANT SCHOlars \\ DURING THE FIRST FIFTY YEARS OF THE REFORMATION \\ JOEL VARELA RODRÍGUEZ \\ UNIVERSITY OF SANTIAGO DE COMPOSTELA
}

Es bien conocida entre los estudiosos de la obra del papa Gregorio Magno la agria polémica que suscitaron dos volúmenes publicados en 1987 por Francis Clark con el objetivo de demostrar que Gregorio no había sido el autor de una de las obras más difundidas y leídas que circularon bajo su nombre: los Dialogi. ${ }^{1}$ Según la argumentación de Clark, la obra fue escrita por un anónimo romano de la segunda mitad del siglo VII (the Dialogist), que se habría servido de fragmentos gregorianos originales conservados en la cancillería pontificia (Inserted Gregorian Passages $=$ IGP), si bien habría sido él mismo el autor del contenido hagiográfico la obra y el que habría atribuido el conjunto al papa Gregorio para conferirle fama y autoridad. Más allá de los muchos y distintos argumentos de crítica externa e interna utilizados por el erudito inglés, los cuales han sido ampliamente debatidos en los últimos años, Clark confiesa en las primeras páginas de su trabajo concordar con la sospecha de inautenticidad de la obra que ya habían manifestado antiguos estudiosos, la mayoría protestantes, desde la

Este artículo es una derivación de la comunicación que pronuncié en la KU Leuven el 7 de noviembre de 2019, durante un seminario en honor del Prof. John Monfasani (The Church Fathers in the Reformation and Early Modern Era). Vuelvo a agradecer desde aquí a los responsables del grupo Lectio su excelente organización y acogida. La investigación se inscribe en el seno de las actividades del Grupo de Investigación 1908 («Estudios Clásicos y Medievales») de la Universidad de Santiago de Compostela.

1 Francis CLARK, The Pseudo-Gregorian Dialogues, 2 vols., Brill, Leiden, 1987 (Studies in the History of Christian Traditions, 37). Años antes, en 1982, había adelantado sus conclusiones en un coloquio celebrado en Chantilly: FRANCIS CLARK, « The Authenticity of Gregorian Dialogues: A Reopening of the Question? », en Jacques Fontaine, Robert Gillet, Stan Pellistrandi (eds.), Grégoire le Grand. Chantilly, Centre culturel Les Fontaines, 15-19 septembre 1982 (Colloques internationaux du Centre National de la Recherche Scientifiques), Éditions du Centre National de la Recherche Scientifique, Paris, 1986, p. 429-443.
\end{abstract}


segunda mitad del siglo XVI. El primero fue Huldreich Coccius, editor de los Opera omnia de Gregorio en la imprenta de Froben, ${ }^{2}$ y los argumentos más refinados, que inspiraron las tesis de Clark, proceden de Robert Cooke y William Cave, ya en la siguiente centuria. ${ }^{3}$ Varios críticos recientes han atribuido a Clark y a todos estos autores un idéntico prejuicio, propio de su aproximación a los padres de la Iglesia: como Gregorio es un autor profundo y en parte correcto en sus escritos teológicos, una obra como los Dialogi suscita tal contraste que cabe pensar que no haya salido de su pluma. Contra esto, la crítica moderna ha respondido aduciendo argumentos que prueban, entre otras cosas, una coherencia entre los Dialogi y el pensamiento que subyace a las otras obras de Gregorio. ${ }^{4}$

No obstante, esta aproximación no caracteriza a todos los lectores protestantes de Gregorio. En un trabajo reciente, Guazzelli ${ }^{5}$ ha puesto de manifiesto el contraste existente entre la edición de Coccius, que conviene con la idea arriba mencionada, y otros dos hitos de la historiografía protestante del siglo XVI: el Catalogus testium veritatis de Matías Flacio Ilírico y las Centurias de Magdeburgo, que no se cuestionan la autenticidad de los Dialogi y los consideran fruto de una religiosidad supersticiosa que habría caracterizado a Gregorio y su época. La diferente apreciación de los Dialogi, según Guazzelli, sería el obstáculo que impide hablar de una unidad en la aproximación protestante a Gregorio.ù

En la presente contribución me gustaría trazar una historia más completa de la recepción protestante de Gregorio Magno en los primeros 50 años de la Reforma, aunque los límites de un trabajo de estas características me obligarán a

2 Opera divi Gregorii Papae huius nominis primi, cognomento Magni, omnia quae extant, nunc iterum accuratione diligentia a mentis multis, uti lector facile passim deprehendet, maxime in libris Epistolarum, repurgata. Quorum omnium elenchum pagina versa exhibebit. Cum Indice duplici, altero rerum, verborum, sententiarum altero locorum S. scripturae explicatorum utroque magne sedulitate conscripto, Froben, Basileae 1551.

3 RoBERTUS Cocus, Censura quorundam scriptorum quae sub nominibus sanctorum et veterum auctorum, a pontificiis passim in eoum scriptis, sed potissimum in quaestionibus hodie controversis citari solent. In qua ostenditur scripta illa, vel esse suppositia, vel dubiae saltem fidei, Impensis Guilielmi Barret, Londini, 1614, p. 209-212; Guilielmus CAVE, Scriptorum ecclesiasticorum Historia Literaria, Typis T. H. et Impensis Richardi Chiswell ad insigne Rosa Coronatae in Coemeterio D. Pauli, Londini 1688, p. 304-305.

4 De manera general pueden citarse los siguientes trabajos: ROBERT GODDING, « Les Dialogues... de Grégoire le Grand. A propos d'un livre récent », Analecta Bollandiana, 106 (1988), p. 201-229; PAUL MEYVAERT, "The Enigma of Gregory the Great's Dialogues: A Response to Francis Clark », Journal of Ecclesiastical History, 39 (1988), p. 335-381; ADALBERT DE VoGÜÉ, "Grégoire le Grand et ses Dialogues: d'après deus ouvrages récents ", Revue d'Histoire Écclesiastique, 83 (1988), p. 281-348; ID., « Grégoire le Grand est-il l'auteur des Dialogues? », Revue d'Histoire Écclesiastique, 99 (2004), p. 158-161.

5 GiUseppe Antonio Guazzelli, «Gregorio Magno nell'erudizione ecclesiastica della seconda metà del XVI secolo », en CLAUDIO LEONARDI (ed.), Gregorio Magno e le origini dell'Europa, SISMEL-Edizioni del Galluzzo, Firenze 2014 (Millennio Medievale, 100), p. 601-618. 
ceñirme a los autores y testimonios más influyentes. ${ }^{6}$ En los años comprendidos entre la década de 1520 y 1560 protestantes y católicos definen y defienden sus propios dogmas y creencias en un contexto de continua disputa, llegando a una posición de desentendimiento mutuo que afectó también al uso y lectura de Gregorio, y, como consecuencia, a una distinta apreciación de los Dialogi. Por otra parte, la lectura del papa abarca un espectro más amplio que la cuestión de la autoría de los Dialogi, que en el siglo XVI constituye todavía una anécdota en un contexto de disputas de otro calado. En este trabajo buscaré también, pues, dar cuenta de qué intereses encontraron los protestantes en las obras de Gregorio y qué evolución tuvieron éstos en el tiempo.

\section{Gregorio Magno entre el humanismo y la Reforma}

La tradición manuscrita de las obras de Gregorio (con alguna notable excepción) es inmensa. De los Moralia in Iob, su escrito más famoso, se conservan alrededor de 1500 testimonios; de las Homiliae in Hiezechielem, 650; otros varios cientos para las Homiliae in Evangelia y los Dialogi. Se conservan también varias decenas de incunables. ${ }^{8}$ Hay asimismo una cantidad notable de florilegios de su obra, principalmente desde el siglo XII, la mayor parte de los cuales permanece sin estudiar. La tradición medieval le hizo parte de los cuatro grandes padres de la Iglesia latina, junto a Ambrosio, Agustín y Jerónimo. Aunque no siempre fue leído con el mismo interés en todas partes, ${ }^{9}$ su influencia en la configuración de la espiritualidad cristiana está fuera de duda, y su carácter de autoridad permanece indiscutido durante la época medieval.

Se puede decir que, por lo general, los humanistas mantuvieron también una buena opinión de Gregorio. Por citar algunos ejemplos, Dante recomendó los

6 Gregorio fue tradicionalmente considerado apóstol de Inglaterra y su recepción entre los protestantes ingleses de este período, por ejemplo, podría merecer atención, a pesar de su dependencia del protestantismo continental en los grandes temas donde Gregorio aparece (misas privadas, primado papal, purgatorio, culto a las imágenes, etc.): cf. STANLEY L. GREENSALADE, The English Reformers and the Fathers of the Church. An Inaugural Lecture delivered before the University of Oxford on 10 May 1960, Clarendon Press, Oxford, 1960, p. 1-20.

7 Su tratado exegético sobre el primer libro de Samuel (In I librum Regum), que ha suscitado dudas de paternidad, se conserva en un único códice del siglo XII y en la tradición impresa.

8 Cf. al respecto los capítulos consagrados al estudio de la tradición de las obras gregorianas por Lucia CASTAldi, La trasmissione dei testi latini del medioevo. Mediaeval Latin Texts and their Transmission. Te.Tra 5. Gregorius I papa, SISMEL-Edizioni del Galluzzo, Firenze 2013 (Millennio Medievale, 98).

9 A partir de un examen de los inventarios medievales, Anne Marie Turkan ofrece el dato de que Gregorio constituyó el referente de la edificación espiritual en el ámbito monástico, principalmente el cluniacense, más que Agustín, que fue referente para otra clase de asuntos: ANNE-MARIE TURKAN-VERLEK, " La place de Grégoire le Grand dans les inventaires de livres avant le XIII siècle », en CLAUDIO LEONARDI (ed.), Gregorio Magno e le origini dell'Europa, SISMEL-Edizioni del Galluzzo, Firenze 2014 (Millennio Medievale, 100), p. 355-396. 
Dialogi como lectura de edificación personal, ${ }^{10}$ y la espiritualidad y las reminiscencias gregorianas son perceptibles a lo largo de su obra, lo mismo que con Petrarca. ${ }^{11}$ Humanistas italianos como Lorenzo Valla, Federico da Montefeltro o Cosimo de' Medici leyeron y se interesaron por la obra y la persona de Gregorio, atraídos por la espiritualidad que emanaba de su historia humana como predicador y político y las reflexiones espirituales de sus escritos. ${ }^{12}$ En España, el canciller Pedro López de Ayala, en su Rimado de palacio, declara hallar consuelo de la corrupción del mundo en la lectura de los Moralia, cuyo contenido parafrasea en gran medida en una extensa sección de la obra, sirviéndose, por lo que parece, de una traducción al castellano que él mismo había hecho. ${ }^{13}$ Todavía Tomás Moro parece haber considerado a Gregorio un autor de mayor importancia que el mismo Agustín. ${ }^{14}$

Es, sin embargo, Erasmo de Rotterdam, el humanista que mayor impulso dio a las ideas reformadas, quien de forma más clara rompe este aparente consenso. Erasmo vio todavía en los Padres un remedio espiritual para la cristiandad y no sólo una fuente de inspiración para comprender la Escritura; sin embargo, no todos los Padres sirvieron a ese propósito. ${ }^{15}$ Gregorio, desde luego, no estuvo entre ellos. A priori, Erasmo no parece haber sido un avezado lector del papa: las citas son pocas y, en alguna ocasión, de segunda mano. ${ }^{16}$ Aunque no llega a las críticas abiertas contra Gregorio que veremos entre los protestantes, importa destacar que nunca editó sus obras, a diferencia de lo que hizo con Ambrosio

10 Cf. al respecto Mariarossa Cortessi, «Gregorio Magno e gli humanisti », en Leonardi (ed.), Gregorio Magno e le origini dell'Europa, p. 577-599.

11 Cf. Carmen Cardelle de Hartmann, "Petrarcas Secretum in den deutschen Klöstern - Die monastische Lektüre eines humanistischen Werkes », en Mathias Dall'Asta (ed.), Anwälte der Freiheit! Humanisten und Reformatoren im Dialog. Begleitband zur Ausstellung im Reuchlinhaus Pforzeim, 20. September bis 9. November 2015, im Auftrag der Stadt Psorzheim, Winter, Heidelberg 2015, p. 81-89.

12 Cf. CORTESSI, « Gregorio Magno e gli humanisti », p. 599.

13 Cf. Hugo O. Bizzarri, Pedro López de Ayala. Rimado de Palacio. Edición, estudio y notas, Real Academia Española, Madrid 2012 (Biblioteca de la Real Academia Española, 8), p. 364-371. Por lo demás, la influencia de Gregorio Magno en la Baja Edad Media y el Renacimiento en España permanece sin estudio específico.

14 Así lo indica Anne Kuzdale, "The Reception of Gregory in the Renaissance and Reformation », en Brownen Neil, MatThew J. Dal Santo (eds.), A Companion to Gregory the Great, Brill, Leiden 2013 (Companions to the Christian Tradition, 47), p. 380.

15 En su última obra, el Ecclesiastes sive de ratione concionandi (1535), los Padres aparecen como un modelo de predicación, pero no sin limitaciones. En esta obra cita los varios doctores prophani et ecclesiastici cuyos escritos debieran ser leídos por un predicador; los que llevan la peor parte son los Padres latinos. Cf. JAN DEN BOEFT, «Erasmus and the Church Fathers », en IRENA BACKUs (ed.), The Reception of the Church Fathers in the West from the Carolingian to the Maurists, Brill, Leiden 1997, p. 537-572.

16 KuzDALE, «The Reception of Gregory », p. 379 alude a una cita en la Paráfrasis de Marcos referida a los Moralia que realmente procedería de la Catena aurea (1265) de Tomás de Aquino. 
(1492), Agustín (1506) o Jerónimo (1516), y manifiesta cierta incredulidad sobre los fundamentos sobre los que dice construirse el canon de los cuatro doctores. ${ }^{17}$ Erasmo tuvo interés por los padres de los primeros siglos, que podían ofrecer una interpretación más pura y correcta de la Escritura y las verdades cristianas, y no tuvo en buena estima los excesos de la interpretación alegórica (en los que pudo haber considerado que Gregorio hubiera caído) ni las vidas de santos e historias de milagros. ${ }^{18}$ Todo ello habría alimentado cuando menos su desinterés por la figura y la obra del papa. Esta aproximación a Gregorio y a los padres será bien perceptible entre los primeros reformadores.

Cabe destacar, por otra parte, que desde el siglo XV la historiografía humanista considera la época de Gregorio como un período de decadencia en todos los factores, la puerta de las tinieblas medievales. Un significativo ejemplo es la Historia ab inclinatione Romanorum imperii de Flavio Biondo, escrita entre 1439 y 1453 y ampliamente leída por los humanistas, que considera el año 410, con el saqueo de Roma por Alarico, el punto de inflexión por el que la cultura occidental entra en una fase de decadencia que dura hasta el siglo XV ${ }^{19}$ El pontificado de Gregorio Magno queda de este modo inmerso en una época de oscuridad donde era perceptible la decadencia moral y material de la sociedad y los hombres. La visión protestante de la historia eclesiástica convendrá igualmente con esta perspectiva, en cuanto que entiende que la Iglesia vio progresivamente cómo se deturpaba su pureza original y entraban en ella creencias y costumbres contrarias al cristianismo primitivo: Gregorio, aunque se tratara de un hombre santo, no escapó a la corrupción religiosa de su mundo, como podremos ver afirmado en varios protestantes del siglo XVI.

17 Cf. en su prefacio a la edición de Jerónimo: « Operae precium est audire censuram istorum, qui cuncta ad certum numerum redegerunt. Doctores ecclesiae quatuor esse libuit: et quatuor item scripturae divinae sensus, nimirum ut respondeant quatuor Evangelistis. Gregorio tribuunt tropologiam, Ambrosio allegoriam, Augustino anagogen, Hieronymo, ne nihil habeat, reliquunt literam, et sensum grammaticum » (cito por la reedición de 1553: Eximii doctoris Hieronymi Stridonensis vita, ex ipsius potissimum scriptis contexta, per Des. Erasmum Roterdamum, en D. Hieronymi operum primus tomus. Epistolas ipsius in tres partes distinctas, ac Des. Erasmi Roterodami scholiis summa cura et diligentia explanatas atque castigatas complectens, Froben, Basileae 1553). Sobre la práctica filológica de Erasmo, cf. ARNOUD VISSER, «Thirtieth Annual Erasmus Birthday Lecture: Erasmus, the Church Fathers and the Ideological Implications of Philology », Erasmus Studies, 31 (2011), p. 7-31.

18 Cf. KUZDALE, « The Reception of Gregory », p. 378-379.

19 Cf. Wallace K. Ferguson, The Renaissance in Historical Thought, Houghton Mifflin Company, Cambridge 1948, p. 11-14. 


\section{Los padres de la Reforma}

\section{II.1 Lutero}

De entre todos los autores protestantes que mencionaré aquí, Lutero es el que mejor prueba da de conocer bien a Gregorio. Aquí y allá cita o alude a interpretaciones gregorianas de la Escritura, sacadas principalmente de los Moralia, una práctica que no veremos en ningún otro gran padre de la Reforma. Hay más de 15 citas o alusiones a Gregorio sólo hasta $1521 .{ }^{20}$ Alguno de sus primeros sermones, como el pronunciado el día de la Epifanía del Señor de 1517, depende largamente de la intepretación gregoriana del oro, el incienso y la mirra que puede encontrarse en una de las homilías sobre Ezequiel. ${ }^{21}$ En otras ocasiones, la mayoría, utiliza a Gregorio para reforzar determinadas interpretaciones de la Escritura que le sirven para argumentar sobre tal o cual materia.

En cualquier caso, la opinión de Lutero sobre Gregorio no estuvo falta de crítica, como hizo con los demás padres. En el plano teológico, podemos leer que Lutero considera que Gregorio « delira » en sus interpretaciones alegóricas de los sentidos ocultos de la Escritura (mysteria) y no presta atención a las verdades fundamentales del cristianismo: "Vide Gregorium, quando delyravit... de fide, nihil de charitate, cruce, semper mysteria tractat $\gg .{ }^{22}$ Se trata de una crítica que, en mayor o menor grado, emerge también en otros padres de la Iglesia, como Cipriano, Agustín u Orígenes, ${ }^{23}$ lo cual no significa, sin embargo, que su desprecio fuera absoluto, como podemos deducir del empleo de Gregorio en sus escritos.

Aunque no es muy común, leemos en Lutero algunas alusiones sinceras a la santidad y otras virtudes de Gregorio, ${ }^{24}$ imagen que una larga tradición hagiográfica le había configurado. No obstante, le considera también un hombre extremadamente supersticioso: "Augustinus est aliquantulum victus supersticione, Gregorius est quasi leprosus supersticione, Hieronimus sordet illa, ita et ego $»{ }^{25}$ Además, consciente de la gran autoridad de que había gozado, le tiene por responsable de incluir tradiciones «humanas» en la Iglesia: «Gregorius, vir sanctus, sed non uno tantum loco superstitiosus, arripuit

20 He consultado las ocurrencias en D. Martin Luthers Werke: Kritische Gessammtausgabe [en adelante WA], Herman Böhlaus, Weimar 1883-1993, 1, 2, 6, 7 y 8.

21 WA 1, p. 122-125. Cf. Greg. M., hom. Ez. 2, 10, ed. MARCus Adriaen, Gregorius Magnus. Homiliae in Hiezechielem prophetam, Brepols, Turnout 1971 (Corpus Christianorum. Series Latina, 142), p. 396-397.

22 WA 16, p. 74.

23 Cf. Johannes Schilling, «Luther un Gregor der Grosse », en Leif Grane, Alfred Schindler, Markus WRIEDT (eds.), Auctoritas Patrum. Zur Rezeption der Kirchenväter im 15. und 16. Jahrhundert, Institut für Europaische Geschichte, Mainz 1993, p. 180.

24 Cf. WA 2, p. 643: « sicut dicit sanctus et humillimus Gregorius ».

25 WA 31 II, p. 302. 
occasionem pro terrendis conscientiis et stabiliendis traditionibus hominum $»{ }^{26}$ Estas reflexiones aparecen cuando Gregorio podría servir para justificar la tradición de prácticas y creencias que él rechazaba como propias del cristianismo primitivo, como son las misas privadas, el purgatorio, la justificación a través de las obras o el culto a los santos. Gregorio, en efecto, es humano, y a pesar de su santidad no siempre interpretó correctamente la Escritura ni el mensaje evangélico. En alguna ocasión, los Dialogi parecen emerger como la cumbre del Gregorio más supersticioso: "Initium celebrationum venit ex apparitione animarum, quae tres, 30 petiverunt legi missas. Gregorius erravit et magnum librum de his rebus scripsit $»{ }^{27}$ sin embargo, no hay ningún lugar donde Lutero dude de la autenticidad de la obra.

Hay que destacar que Gregorio también acredita para Lutero la pervivencia de una cierta pureza en la Iglesia de su tiempo. Es a partir de él cuando se puede hablar realmente del fin de esa pureza primigenia. ${ }^{28}$ Lutero presta singular atención al papel de Gregorio en la cuestión de la primacía papal, que se halla en el centro de sus primeras grandes polémicas después de 1518. Lutero, como hará el resto de protestantes interesados por esta materia, halla en las epístolas gregorianas firmes argumentos en contra de la existencia de una primacía del papa sobre los restantes obispos de la Iglesia. En efecto, Gregorio había criticado en varias de sus cartas el que Juan IV de Constantinopla se arrogara el título de patriarca ecuménico, una situación que, aunque no suponía gran novedad en la Iglesia de fines del siglo $\mathrm{VI}{ }^{29}$ le valió a Gregorio palabras de condena contra la pretensión de erigirse como cabeza de la Iglesia sobre el conjunto de los obispos, considerando que era una potestad que sólo Cristo tenía. Ello le sirve a Lutero para argumentar que el primado universal del obispo de Roma no tenía fundamento en la tradición antigua de la Iglesia, y que aún en tiempos de Gregorio era un concepto que no se había desarrollado. Cita a Gregorio en este sentido tan pronto como en 1518: "Nam adhuc S. Gregorii tempore Romanus Pontifex, universalis Episcopus, acerrime persequitur nomen universalis Episcopi

WA 8, p. 453.

WA 11, p. 130.

8 Cf. WA TR 4, p. 255: "Primum tempus conciliorum est a tempore apostolorum usque ad Gregorium Primum, ubi Ecclesia aliquatenus fuit purior, quamquam multum humani patiebatur, sed tamen tolerabilis fuit ». En línea con lo que se dirá inmediatamente, hay que destacar que al final de su vida, en su Supputatio annorum mundi (1541), escribe que Gregorio fue realmente el último " obispo de Roma », y que los que le siguieron son en realidad "pontífices de la curia romana », haciendo así de Gregorio - si interpretamos literalmente sus palabras - el último obispo romano en conservar la pureza de su auténtica dignidad apostólica: « Gregorius magnus ultimus Episcopus Romanae Ecclesiae, sequentes sunt Pape, id est Pontifices Romanae Curiae» (WA 53, p. 142).

29 Cf. ANDRÉ TUILLIER, "Grégoire le Grand et le titre de patriarche oecuménique », en FonTAINE, Gillet, Pellistrandi (eds.), Grégoire le Grand. Chantilly, p. 69-82. 
et totius Ecclesiae pontificis plus fere sex epistolis, etc. ». ${ }^{30} \mathrm{Y}$ el de Gregorio será un argumento relevante en este sentido en la disputa con Johann Eck sobre la primacía del papa el año siguiente. ${ }^{31} \mathrm{~A}$ partir de aquí, la consideración de Gregorio sobre la primacía universal de la Iglesia será aducida sistemáticamente por los protestantes en contra del papado.

En conclusión, podemos decir que, para Lutero, Gregorio era un hombre santo y piadoso, si bien también afectado por creencias humanas ajenas a la realidad de la Revelación (superstitiosus), en la línea de la decadencia de su tiempo, aunque su interpretación de la Escritura, pese a su tendencia alegorista, no siempre le resulta despreciable. Además, las cartas de Gregorio sobre la polémica con Juan de Constantinopla son para Lutero una fuente de importancia para sostener su polémica sobre la cuestión de la primacía papal.

\section{II.2 Zwinglio}

Aparentemente, la opinión de Zwinglio sobre Gregorio como autoridad teológica se inscribe en la línea de su percepción de los demás padres de la Iglesia, que no diverge de la de un humanista de influencia erasmiana. El 29 de enero de 1523, preguntado por un ciudadano en una controversia de Zurich si era lícito leer a Ambrosio o a Gregorio, Zwinglio respondió que ambos son autores que se podían leer, pero en cuanto ayudan a la comprensión de la Escritura, a través de la cual se califica su valor. ${ }^{32}$

Sin embargo, sus citas de Gregorio no son muchas, y ni mucho menos parece que Zwinglio tuviera el mismo interés que Lutero por la obra del papa. ${ }^{33} \mathrm{~A}$ diferencia de lo que ocurre con otros Padres de la Iglesia, no conocemos ningún ejemplar de obra alguna de Gregorio que hubiera sido ante todo por él. ${ }^{34}$ En algún lugar alude a Gregorio y sus Moralia como ejemplo de un alegorismo excesivo empleado cuando falla la verdadera comprensión de la Escritura, ${ }^{35} \mathrm{si}$ bien esto no sería un problema si hubiera aprovechado lo que en Gregorio pudidera hallar de correcto, como hizo Lutero; no obstante, es claro que Zwinglio prefirió a otros

\section{WA 2, p. 20.}

Cf. WA 2, p. 280.

Cf. Huldreich Zwinglis sämtliche Werke, vol. I, Schwetschke, Berlin 1905, p. 564.

AlfRed SCHINDLER, Zwingli und die Kirchenväter, Beer, Zürich 1984 (Neujahrsblatt zum Besten des Waisenhauses Zürich, 147), p. 94 cuenta 30 citas o alusiones a Gregorio, frente a las más de 1500 de Jerónimo o las 1000 de Agustín; además, varias de ellas son dudosas, pues pueden referirse a otros papas del mismo nombre.

34 Cf. Irena Backus, "Uldrich Zwingli, Martin Bucer and the Church Fathers ", en EAD. (ed.), The Reception of the Church Fathers, p. 635.

35 Huldrici Zuinglii Opera. Completa editio prima, ed. Melchiore Schulero et Io. Schulthessio, vol. V, Ex officina Schultessiana, Turici 1835, p. 594: «Qui quicquid non intelligunt, allegoriam faciunt, profitentes interim divinorum librorum enarrationem. Cuius farinae sunt ferme omnes quos hactenus videre licuit, in Psalmorum librum commentarii, et Gregorii in Iob moralia ». 
padres como Agustín o Jerónimo. En el mismo sentido, Zwinglio considera que las reformas litúrgicas de Gregorio enfatizaron el culto supersticioso de los santos; Gregorio es el representante de una época de ruptura respecto a la pureza de la cristiandad anterior. ${ }^{36}$

Sea como fuere, Gregorio era una autoridad consolidada y Zwinglio no deja de dar muestras de un cierto respeto por ella. En un tratado sobre el canon de la misa escrito en 1523, considera posible certificar la paternidad gregoriana de una plegaria del misal que se le venía atribuyendo de antiguo («Diesque nostros in tua pace disponas, atque ab aeterna damnatione nos eripi et in electorum tuorum iubeas grege numerari »), en razón de su elegancia, que considera propia del autor, en contraposición a las demás partes del canon. ${ }^{37}$

También cabe dar cuenta de lo que parece una cita de segunda mano, que es además una de las pocas veces en las que se citarían literalmente palabras del autor. La presencia de una cita de Gregorio acreditaría en este caso un conocimiento antológico para un uso esporádico, no tanto una reflexión y maduración del contenido leído en el autor, como parece ser por el contrario el caso de Lutero. Se halla en unas notas al Evangelio de Mateo (en concreto, Mt 12, 30), publicadas póstumamente por Leo Jud en 1539:

Tracta autem est metaphora a messis tempore, ubi omnes currunt et colligunt futuram tempestatem metuentes; qui hoc non faciunt, si quid perit aut dispergitur, culpa eorum perditur. Sic in negotiis divinis, qui bonum non promovet, malum promoveat necesse est. Sic Gregorius dicebat: 'In via Dei stare retrogradi est'. Hac ergo sententia admonet Christus vehementer et simul eorum malitiam protrahit. ${ }^{38}$

En realidad, la cita no es de Gregorio, sino de Bernardo de Claraval (serm. II in festo Purif. n. 3), y está bastante difundida desde la Baja Edad Media. La primera atribución de un adagio semejante a Gregorio se halla, por lo que he podido

36 Cf. Huldreich Zwinglis sämtliche Werke, vol. I, p. 515.

37 Huldrici Zuinglii Opera. Completa editio prima, ed. Melchiore Schulero et Io. Schulthessio, vol. III: Didactica et apologetica, Ex officina Schultessiana, Turici 1832 p. 103: "'Diesque nostros in tua pace disponas, atque ab aeterna damnatione nos eripi et in electorum tuorum iubeas grege numerari'. Hanc tandem huius precationis partem Gregorio, ut diximus, adscribunt, nos totam. Hic autem videre licet quam stilus canonis totus a veterum dictione abhorreat: nam non alibi per omnem canonem orationem elegantiorem invenies quam sit ista, meliusque expensam, quamquam utrumque mediocriter. Sive Gregorii sit, sive non sit, nos eius esse propter elegantiam solummodo permittimus, numquam alioqui credituri quod homo tam pius et doctus ad tam barbarum canona quicquam additurus fuerit ». La atribución a Gregorio de esta plegaria procede de la biografía de Juan Diácono (Vita s. Gregorii Magni 2, 17: PL 75, col. 94A).

38 In evangelicam historiam de Domino nostro Iesu Christo, per Mattheaem, Marcum, Lucam, et Ioanem conscriptam, Epistolasque aliquot Pauli, Annotationes D. Huldrychi Zvinglii, per Leonem Iudae exceptae et editae, Excudebat Christophorus, Tiguri 1539, p. 65. El subrayado es mío. 
encontrar, en Tomás de Aquino. ${ }^{39}$ La confusión debe de provenir, a mi juicio, de un pasaje de la Regula pastoralis donde Gregorio compara la vida presente con un río, donde el que no busca hacer progresos necesariamente retrocede. ${ }^{40}$ Desconozco cuál pudo haber sido la fuente concreta aquí. Ahora bien, hay que apuntar que la frase con la cita de Gregorio está ausente en la versión de este texto del manuscrito Zürich, Zentralbibliothek, Z V 370, fechado en 1535, que es aparentemente copia de unos apuntes de Zwinglio sobre el Evangelio de Mateo, realizada por una mano desconocida. ${ }^{41}$ Con esto podría quedar en entredicho el que realmente Zwinglio hubiera incorporado la cita.

En conclusión, tomando por base lo que tenemos, cabe deducir que, si bien Zwinglio considera, al menos en apariencia, que Gregorio es susceptible de explicar la verdad de la Escritura, lo cierto es que la presencia gregoriana en la obra del reformador suizo es marginal. Gregorio es una autoridad que, con sus errores (culto a los santos, alegorismo excesivo), sigue siendo reconocida por él, pero en realidad su exégesis y teología no parecen haberse visto inspiradas por el pensamiento del papa, y sólo muy raramente se le cita.

\section{II.3 Melanchthon y las Confesiones de Augsburgo}

Entre los primeros reformados, fue quien más se preocupó de trazar una historia de la Iglesia que refleja la pureza de su estado primitivo y la larga decadencia que va desde la caída del Imperio romano hasta el fin de la Edad Media. Llegó a escribir, de hecho, algunas monografías sobre esta cuestión (así el De ecclesia et autoritate Verbi Dei, publicado en 1539, o el De Luthero et aetatibus Ecclesiae, en 1548). La idea, como sabemos, no es nueva, está muy engarzada en la visión humanista de la historia, pero a Melanchton le cupo no pocas reflexiones, que se remontan como mínimo a su discurso inaugural como profesor en Wittenberg en $1518 .^{42}$

Su visión de los Padres es similar a la de los demás eruditos de la Reforma: tienen autoridad para mejor comprender la Escritura, pero deben juzgarse a

39 Thomas de Aquino, Summa theologiae, II-II, q. 19, a.6, ob. 3: « Praeterea, Gregorius dicit quod in via Dei stare retrocedere est ».

40 GRegorius Magnus, Regula pastoralis, 3, 34 (PL 77, 119A): « Si anima quod mortuum in nobis est, ad vitam non accenditur, hoc etiam extinguitur quod quasi adhuc vivum tenetur. In hoc mundo humana anima quasi more navis est contra ictum fluminis conscendentis, uno in loco stare non permittitur, quia ad ima relabitur, nisi ad summa conetur ».

41 En lugar de la frase subrayada encontramos: « Sic in re divina, qui bonum non facit et promovet, hic et malum facit et promovet»; cf. Huldreich Zwinglis Sämtliche Werken, vol. XX: Exegetische Schriften 8: Neues Testament. Evangelium nach Matthäeum (die andere Parallelüberlieferunt zu den Bänden XVII und XIX) nach dem Manuskript in den Zentralbibliothek Zürich: Ms Z V 370, ed. M. Lienhand, D. Bolligen, Tübingen 2013, p. 97.

42 Cf. al respecto Peter Fraenkel, Testimonia patrum. The Function of the Patristic Argument in the Theology of Philip Melanchton, Librarie E. Droz, Genève 1961, p. 15-24. 
partir de ésta. Por lo que a Gregorio se refiere, Melanchton repite a las mismas críticas en lo doctrinal que Lutero: es culpable de haber importado a la Iglesia tradiciones humanas vindicadas por el catolicismo romano, como el celibato, las misas de difuntos o las misas privadas, y en definitiva corrompió la doctrina de la salvación por la fe. ${ }^{43}$ Gregorio no parece haber influido positivamente en su pensamiento doctrinal. ${ }^{44}$ Como señaló Fraenkel, Gregorio supone para Melanchton una figura de transición que consolida el 'pelagianismo' en la Iglesia de forma definitiva, con duras consecuencias para la vida cristiana hasta los tiempos recientes.

No obstante, Melanchton no duda de su piedad ni de su capacidad para el buen gobierno de la Iglesia: llega a lamentarse en una carta (15 de marzo de 1550) que no quede en su tiempo ningún Gregorio capaz de tratar con los temas políticos en que se ve envuelto. ${ }^{45}$ Desde el punto de vista de su formación, Gregorio sería un hombre de excepción, más propio de la 'tercera edad' de la Iglesia que tuvo a su mejor representante en Agustín que de los tiempos en que realmente vivió, una figura ya fuera de lugar en las tinieblas de una época que se alargaron hasta el advenimiento de Lutero. ${ }^{46}$ La razón de los errores de Gregorio parecen ser más bien fruto de la decadencia de los tiempos, a las que ni siquiera él escapó, pues las invasiones bárbaras que terminaron con el poder político del Imperio romano lo hicieron también con la cultura antigua. Los bárbaros incluso trajeron consigo costumbres paganas que, de alguna manera, y en cierto modo sustentadas por la autoridad de Gregorio, pervivieron en el catolicismo romano. ${ }^{47}$

En 1530, con el fin de presentar una exposición de sus posturas en la Dieta de Augsburgo convocada por Carlos I, los protestantes redactan una profesión de fe, conocida hoy como Confesión de Augsburgo (Confessio Augustana), redactada tanto en latín como en alemán. La Confesión viene con un largo apéndice donde se enuncian y refutan los 'abusos' en que había incurrido la Iglesia católica en numerosas materias, y es claramente dependiente de la teología de Lutero. Melanchthon debió de tomar parte activa en la redacción del texto, en cuya

43 Análisis y convenientes citas al respecto en FrAENKeL, Testimonia patrum, p. 96-97.

44 Ni una sola cita de Gregorio a este respecto recoge Eginhard Peter MejJering, Melanchton and Patristic Thought. The Doctrine of the Grace, The Trinity and the Creation, Brill, Leiden, 1983.

45 Cf. Carolus Gottliebt Bretschneider (ed.), Philippi Melanthonis opera quae supersunt omnia, Apud C. A. Schwetscchk et filium, Halis Saxonum, 1840 (Corpus Reformatorum, 7), col. 561.

46 Cf. De Lutero et aetatibus Ecclesiae, in Philippi Melanthonis opera quae supersunt omnia, ed. CARoLus GotTliebT BRETSCHNeIDER, Apud C. A. Schwetscchk et filium, Halis Saxonum 1843 (Corpus Reformatorum, 11), col. 783-788.

47 Cf. FraenKel, Testimonia patrum, p. 96-100. Ejemplos de esas supersticiones paganas son la popularidad del monacato, el sistema escolástico (traído por los escotos al continente), e incluso el sistema de satisfacciones: «Olim erant quaedam homidarum et aliorum pollutorum signa, ut Orestes, Oedipi. Ex hac disciplina veteri et civili mos ortus est satisfactionum, de quo non intellecto quam futiles opiniones finxerunt Monachi? », del segundo párrafo a los Loci communes de 1541, citado por FRAENKEL, Testimonia patrum, p. 100, nota 247. 
versión latina (pero no en la alemana) se alude a Gregorio como el primer testimonio de la realización de misas privadas (« nam ante Gregorium non faciunt mentionem privatae Missae $\gg) ._{.}^{48}$ Ese mismo año, tras recibir la respuesta católica (Confutatio pontificia) a la Confesión, el propio Melanchthon redacta una nueva versión del texto (Apologia confessionis Augustanae) donde, tras aclarar que Cipriano y Jerónimo no hablaron nunca de la invocación de los santos, se alude a Gregorio nuevamente como el primero de los antiguos escritores que hace referencia a dicha práctica («neque reliqui veteres Scriptores ante Gregorium fecerunt mentionem invocationis $\gg),{ }^{49}$ una afirmación que tiene con seguridad su base en los Dialogi. Asimismo, se especifica que aunque Gregorio pueda ser tomado como autoridad para sustentar determinadas prácticas defendidas por los católicos - como en efecto se hizo en la Confutatio pontificia,$-{ }^{50}$ las Escrituras van en su contra, las cuales ciertamente a veces contradicen a los padres:

Quod vero allegant adversarii Patres de oblatione pro mortuis. Scimus veteres loqui de oratione pro mortuis, quam nos prohibemus, sed applicationem Coenae Domini pro mortuis ex opere operato, improbamus. Nec patrocinantur adversariis Veteres de opere operato. Et ut maxime Gregorii aut recentiorum testimonia habeant, nos opponimus clarissimas et certissimas scripturas. Et patrum magna dissimilitudo est. Homines erant et labi ac decipi poterant. ${ }^{51}$

En 1540 Melanchthon escribió una profunda revisión del texto, hoy conocida como la Variata, donde introdujo cambios teológicos relevantes, el más notable en el artículo que corresponde a la Eucaristía, donde se elimina la referencia explícita a la presencia real del cuerpo y la sangre de Cristo. La modificación estaba encaminada a la reconciliación con las tesis de Calvino, que de hecho suscribió esta nueva profesión de fe. Por lo que se refiere a Gregorio, no se produce ningún cambio respecto de la Apologia.

Como podemos comprobar, pues, en las Confesiones toma carta de naturaleza el papel de Gregorio como introductor de prácticas religiosas ajenas a la pureza original de la Iglesia. A diferencia de otros autores como Agustín, no hay ninguna referencia al papa para justificar los dogmas protestantes. Puede defenderse que se alude a Gregorio entre los demás padres, de modo que implícitamente se le

48 Confessio Augustanae, xxIv, in Die Bekenntnisschriften der Evangelisch-Luterischen Kirche. Vollständige Neuedition, ed. IRENE DinGEL, Vadenhoeck \& Ruprecht, Göttingen 2014, p. 147. La misma idea figura en la Apologia confessionis Augustanae, xxIv, ed. DINGEL, p. 617, donde la versión alemana recoge esta vez sí la referencia a Gregorio (ibid., p. 618).

49 Apologia confessionis Augustanae, XXI, ed. DinGEL, p. 561. Esta vez sí, la misma idea se recoge en la versión alemana (ibid., p. 560).

50 Cf. HeRbert ImmenKötTeR, Die Confutatio der Confessio Augustana vom 3. August 1530, Aschendorff, Münster 1979 (CCath, 33), p. 73-207. Gregorio Magno aparece citado tres veces en este texto.

51 Apologia confessionis Augustanae, xxIv, ed. DINGEL, p. 659-661. 
reconoce una cierta autoridad, si bien habremos de esperar a una obra como las Centurias de Magdeburgo para hallar una valoración de conjunto de la persona y la obra de Gregorio bajo una óptica protestante.

\section{II.4 Calvino}

La evolución de la apreciación de Gregorio por Calvino fue objeto de estudio en un trabajo de Lester Little, ${ }^{52}$ el cual puso de manifiesto que, si bien las ediciones de la Institutio christianae religionis posteriores a 1543 tenían en Gregorio al padre de la Iglesia más citado después de Agustín, las dos ediciones previas, de 1536 y 1539 respectivamente (la definitiva no sería publicada hasta 1559), carecían de la mayor parte de citas gregorianas. Parece, pues, que durante su exilio en Estrasburgo, donde recaló tras su primer período en Ginebra en 1538, Calvino pudo leer y meditar ampliamente a Gregorio. Ahora bien, hay que indicar que las citas y referencias incorporadas en 1543 son de orden relativo a la historia de la Iglesia y están sacadas en su mayoría del magno conjunto de epístolas de nuestro autor, que parece el texto gregoriano que mejor conoció y meditó Calvino.

En este sentido, podría sospecharse también de que Calvino no llegara a leer todas las obras de Gregorio. Little apunta cómo alguna cita sobre el deber de predicación del clérigo debiera estar sacada antes de la Regula pastoralis que de las cartas o las Homiliae in Hiezechielem, como es el caso. ${ }^{53}$ La cuestión me parece tanto más curiosa cuanto que ya para cuando Calvino estudiaba en París existían ediciones de los opera omnia de Gregorio, incluso publicados en la misma ciudad. Se han localizado también fuentes de las Homiliae in Evangelia, alguna de segunda mano, indicada por el propio Calvino. ${ }^{54}$ Lane contabiliza un total de 29 citas en la Institutio y 30 en otras obras. ${ }^{55}$

Parece que la visión que Calvino tuvo de Gregorio en su madurez fue de admiración hacia su desempeño como pastor y guía de almas, tanto más cuanto que, según deja ver en su Institutio, concibe la época en que el papa vivió como un período en que la pureza de la Iglesia primitiva había entrado en decadencia,

52 LESTER K. LiTTLE, «Calvin's Appretiation of Gregory the Great », The Harvard Theological Review, 56 (1963), p. 145-157. El autor considera que la inspiración de la eclesiología de Gregorio tuvo un papel fundamental en la organización de la vida religiosa y política que Calvino implantó en Ginebra: «First, of course, there was Augustine - his ideological mentor; (...). Finally, there was Gregory, the Roman scholar, who had designed the institutional structure of early Christianity without violating its integrity, and who gave courage thereby to the reluctant architect of the Reformed Church at Geneva » (p. 157).

53 LiTTLE, «Calvin's Appretiation of Gregory the Great », p. 148.

54 Se trata de Inst. III, IV, 1, donde Calvino cita hom. Ev. 14, 15, referida a través de Pedro Lombardo. Cf. ERIK A. De BoER, John Calvin on the Visions of Ezekiel. Historical and Hermenutical Studies in John Calvin's 'sermons inédits', Especially on Ezek. 36-48, Brill, Leiden-Boston 2004 (Kerkhistorische Bijdragen, 21), p. 25.

55 Anthony N. S. LANE, John Calvin Student of Church Fathers, T\&T Clark, Edimburg 1999, p. 62-66. 
como ya había hecho Lutero. Según su visión de la historia, fue la decadencia de los reinos en esta época lo que facilitó el acrecentamiento del poder del obispo de Roma, con el consecuente desvío moral de su estado originario, ${ }^{56}$ si bien Gregorio parece preservar la pureza primitiva en lo que se refiere a la administración de los asuntos eclesiásticos. ${ }^{57}$ En efecto, el desempeño de Gregorio como obispo parece corresponderse, según Calvino, con el propio del estadio puro de la Iglesia: una suerte de cabeza escogido por los presbíteros para guardar de la disensión que es consecuencia de la igualdad, pero sin mayores potestades espirituales, ni un poder especial sobre ellos. ${ }^{58}$ Gregorio se habría arrogado poderes terrenales sobre el poder civil; antes bien, se habría comportado como un fiel súbdito del emperador. ${ }^{59}$ Por otra parte, la eclesiología gregoriana, fundamentada en categorías que ciertamente van más allá de la ordenación de la Iglesia de su tiempo y buscan una vinculación trascendente con la mística evangélica (Gregorio habla de pastores y rectores, no de clerici o episcopi, por ejemplo), ${ }^{60}$ parece haber sido percibida por Calvino como prueba de que el papa concebía todavía la ordenación eclesiástica en su forma primitiva y pura. Gregorio entiende que la función principal de todos los pastores es la predicación de la Palabra de Dios, una función que para Calvino la Iglesia católica no había conservado, y que considera necesario restituir. ${ }^{61}$

56 Inst. IV, VII, 12: «Gregorii tempore iam multum mutata erat prisca illa ratio. Convulso enim lacerato imperio, cum Galliae et Hispaniae multis subinde acceptis cladibus afflictae essent, vastatum Illyricum, vexata esset Italia, Africa vero assiduis calamitatibus fere perdita: quo in tanta rerum civilium convulsione fidei saltem integritatas maneret, aut certe non prorsus interiret, omnes undique Episcopi se ad Romanum Pontificem magis adiunxerunt. Eo factum est ut sedis non modo dignitas, sed etiam potentia vehementer cresceret » (cita de la edición de 1559, Joannis Calvini Opera selecta, vol. V: Institutionis Christianae religionis 1559 librum IV. continens. Editio secunda emendata, reimpresa en Wipf \& Stock, Eugene 2018, p. 115). Cf. también Inst. IV, XI, 14.

57 En este sentido, Calvino llega a contraponer la situación de la sede romana con Gregorio, todavía en un estado de pureza, a la de tiempos de San Bernardo, donde la decadencia sería ya similar a la de su propia época. Cf. Inst. IV, vII, 22.

58 Cf. Inst. IV, IV, 13 y 15.

59 Cf. Inst. IV, XIX, 10. Nótese además que Calvino dice expresamente que Gregorio no citó nunca la Donación de Constantino (Inst. IV, XI, 12), aportando un argumento más en prueba de su falsedad.

60 Cf. BRuno Judic, « Il vescovo secondo Gregorio Magno », en Claudio Leonardi (ed.), Gregorio Magno e le origini dell'Europa, SISMEL-Edizioni del Galluzzo, Firenze 2014 (Millennio Medievale, 100), p. 269.

61 Inst. IV, IV, 3: «Ea igitur fuit temporum illorum severitas, quale ab ipsis Dominus requirit, adigerentur. Nec unius tantum aetatis morem refero: siquidem ne Gregorii quidem tempore, quo Ecclesia iam fere collapsa erat (certe multum ab antiqua puritate degeneraverat) tolerabile fuisset episcopum aliquem a concionibus abstinere » (Joannis Calvini Opera selecta, p. 60). Y cita como ejemplo pasajes de las cartas y las Homiliae in Hiezechielem. En el mismo sentido Inst. IV, IV, 5. Cf. la interpretación de LITTLE, «Calvin's Appretiation of Gregory the Great », p. 151-152. 
Gregorio sirve a Calvino también como fuente para otras cuestiones de correcta disciplina y ordenación eclesiástica que habrían sido deturpadas y corrompidas en la historia de la Iglesia. Calvino cita ampliamente, como otros antes que él, la disputa de Gregorio con Juan de Constantinopla como fuente para el rechazo de la primacía universal del obispo de Roma. ${ }^{62}$ Además, cita a Gregorio como prueba de que en la Iglesia primitiva se administraba el vino a los fieles en la Eucaristía. ${ }^{63}$

La visión que Calvino tuvo de Gregorio parece, pues, un tanto más positiva que la de otros reformados, en cuanto que ve en él un hombre que había conservado la pureza primitiva de su dignidad sacerdotal en un tiempo donde la corrupción había ya penetrado en la Iglesia. No quiere esto decir, por supuesto, que viera en él a un hombre sin mancha de esa corrupción: hay una cita del libro I de la Institutio donde, aun sin citar fuente alguna, apunta que defendió el culto a las imágenes (denostada por Calvino, cuya inconoclastia es conocida), contra el precepto del Espíritu Santo, ${ }^{64}$ una apreciación crítica que aparece en otras obras suyas; ${ }^{65}$ no obstante, parece intuirse que la espiritualidad gregoriana le resultó agradable e inspiradora, al menos en lo que respecta a la visión de la Iglesia y el ejercicio de la cura de almas, una visión basada en la lectura de las cartas y las homilías. ${ }^{66}$ Por lo que podemos deducir, la percepción que Calvino tuvo de Gregorio fue original y muy personal, sin verse condicionada por la autoridad que Gregorio podía tener en el plano exegético o teológico.

2 Cf. Inst. IV, vil, 4-22.

63 Cf. Inst. IV, XVII, 49.

64 Inst. I, XI, 5: «Scio quidem illud vulgo esse plusquam tritum, libros idiotarum esse imagines. Dixit hoc Gregorius, at longe aliter pronuntiat Spiritus Dei, in cuius schola si edoctus fuisset hac in parte, nunquam ita loquutus foret ».

65 Cf. por ejemplo In Ieremiam 10, 8, esta vez sí citando su fuente: "Celebris est illa sententia Gregorii ad Serenum episcopum Massiliensem: nam bonus ille vir deicerat imagines, quas videbat prostare ad impium cultum, et purgaverat etiam omnia Massiliae templa illis inquinamentis: Gregorius quamvis esset pius vir, tamen rescriptsit nimis stulte, recte fecisse et prudenter Serenum quod vetuisset imagines coli: sed tamen hoc fecisse inconsiderate, quod templa vacuasset: nam sunt, inquit, libri idiotarum: haec est clausula epistolae " (EDUARDUS Reuss, Alfredus Erichson, Guilielmus Baldensperger [eds.], Ioannis Calvini opera exegetica et homiletica ad fidem editionum authenticarum cum prolegominis literariis, annotationibus criticis et indicibus, vol. XVI, Apud C. A. Schwetscheke et filium, Brunsvigae 1888 [Corpus Reformatorum, 66], p. 68-69). En el mismo sentido In Habacuc 2, 19.

66 LiTTLE «Calvin's Appretiation of Gregory the Great», p. 157 apunta que, en su prefacio al comentario de los Salmos, Calvino se lamenta de que la Providencia no le hubiera permitido permanecer tranquilo en un único lugar como le pedía su natural temperamento, en lo que podría haber un eco del prefacio de los Dialogi, donde Gregorio se lamenta de tener que ocuparse de los tumultos del siglo, mientras en su interior anhela la vida contemplativa del monasterio. Sin negar que Calvino pudiera haber leído los Dialogi, una obra que desde luego no le habría inspirado en mayor medida, lo cierto es que esta clase de ideas pueden hallarse también en otros lugares de la obra gregoriana: cf. por ejemplo Greg. M., Epist. 1, 5. 


\section{La edición de Huldreich Coccius}

Entre los últimos años del siglo XV y las dos primeras décadas del XVI las obras de Gregorio Magno fueron publicadas en multitud de imprentas diferentes; no obstante, parece que a partir de 1520 se produce un descenso, acaso producido por la publicación y difusión de opera omnia en lugar de las obras separadas del autor. La primera edición en tal formato vino a cargo de la imprenta de Bertold Rembolt en París, y se reimprimió en 1533 y 1542. Entre 1520 y 1550, el catálogo provisional elaborado por Kuzdale da dos ediciones de los Moralia in Iob (1521 y 1530) y seis opera omnia (1521, 1523 [reeditado en 1533], 1539, dos de 1540 y 1542), todos ellos salidos de imprentas en París o Lyon. ${ }^{67}$ Ninguna nueva edición aparece localizada en ámbito protestante.

En 1550, la prestigiosa imprenta de Froben en Basilea (donde Erasmo había publicado sus ediciones de los restantes "doctores de la Iglesia latina », como vimos más atrás) publica un segundo tomo de los opera omnia de Gregorio. ${ }^{68} \mathrm{El}$ primer tomo, con las obras restantes, aparece el año siguiente, ${ }^{69}$ incluyendo una carta preliminar del principal responsable de la edición, el profesor Huldreich Coccius, fechada a 15 de marzo de $1551 .^{70} \mathrm{El}$ destinatario de la carta fue Wolfgang Waidner, teólogo protestante de Worms. Coccius fue un personaje relevante de la vida cultural suiza de estos años, profesor de griego y teología, y varias veces rector de la Universidad de Basilea. ${ }^{71}$ Por lo que dice en la carta, su principal labor parece haber sido la de preparar los indices que se contienen en el tomo de 1551, a petición de los impresores. ${ }^{72}$ Aunque el título de la edición afirma que el texto fue sometido a corrección («a mendis multis... repurgata »), Coccius no da ninguna indicación en ese sentido. La edición viene introducida además por una colección de textos relativos a la persona y la obra de Gregorio Magno: las

67 KuZDALE, «The Reception of Gregory », p. 383-386.

68 B. Gregorii papae operum secundus tomus complectens aliquot sacrae scripturae expositiones: tum homiliae super Ezechielem, et in Evangelia: tum eiusdem Epistolas, cum quibusdam aliis, uti verba facie apparebit, Froben, Basilaeae 1550.

69 Opera divi Gregorii papae huius nominis primi, cognomento Magni, omnia quae extant, nunc iterum accuratione diligentia a mendis multis, uti lector facile passim deprehendet, maxime in libris Epistolarum, repurgata. Quorum omnium elenchum pagina versa exhibebit. Cum Indice duplici, altero rerum, verborum, sententiarumque, altero locorum S. scripturae explicatorum, utroque magna sedulitate conscripto, Froben, Basileae 1551.

70 Kuzdale pone como fecha original de la edición de Froben el año de 1544, pero no he conseguido certificarlo.

71 Sobre la vida y trabajos de este personaje puede consultarse Rudolf THommen, Geschichte der Universität Basel, 1532-1632, C. Detloffs Buchhandlung, Basel,1889, p. 353-354.

72 Así lo admite de pasada cuando le recuerda a Waidner el encuentro que ambos habían tenido el año anterior, en el que acabaron hablando de Gregorio Magno: " Porro in ea quae dixi collatione inter caeterea perventum est et ad B. Gregorii cognomento Magni opera, quae tum in manibus versabam ob indicem concinnadum, efflagitantibus id typographis nostris... » (cf. Opera divi Gregorii papae huius nomine primi, p. B2). 
biografías de Juan Stella, Platina, Juan Laziardo y otra anónima, un epitafio del autor, un símbolo de fe a él atribuido y un Miraculum de inventione librorum Moralium beati Gregorio (una de las versiones de la Visio Taionis); no obstante, estos textos parecen ya figurar en la tradición previa de los opera omnia anteriores, ${ }^{73}$ por lo que Coccius o los impresores se habrían limitado a reproducir el corpus introductorio de un modelo anterior. Lo mismo ocurre con los índices: es bastante posible que Coccius hubiera trabajado sobre alguno de los preexistentes, introduciendo los cambios o ampliaciones que considerara convenientes. ${ }^{74}$

Es interesante comprobar que la edición es lo suficientemente precavida para no suscitar demasiados desaires en el mundo católico, donde también circuló y fue leída. La inclusión del Miraculum, por ejemplo, es bastante significativa, y puede deberse más al interés de la imprenta o de sus financiadores que al del propio Coccius, que, como veremos, no parece tener en buena estima este tipo de textos. En cualquier caso, Coccius, que alaba el juicio crítico sin extremismos de Waidner ${ }^{75}$ no explicita ningún error doctrinal de Gregorio, por más que asuma que - como con todos los padres - su lectura pueda suscitar escrúpulos o precauciones. ${ }^{76}$ Menciona algunos puntos de la obra de Gregorio donde pueden leerse reflexiones piadosas sobre la pastoral, ${ }^{77} \mathrm{la} \mathrm{fe},{ }^{78}$ la escatología ${ }^{79} \mathrm{y}$ otros

73 Puedo certificar que dicho corpus aparece en Divi Gregorii Papae, huius nomini primi, cognomento Magni, Omnia quae extant opera, Hugues de La Porte, Lyon 1542. No me ha sido posible consultar el resto de ediciones previas de los Opera omnia.

74 Los opera omnia publicados en Lyon en 1542, citados en la nota anterior, presentan los mismos tipos de índices, aunque su contenido no es siempre el mismo.

75 Opera divi Gregorii papae huius nomine primi, p. B2: « ...ut de scriptorum veterum ac recentiorum monumentis disputares, non eo sane modo, quo hodie solent plerique, temere vel reicientes, vel approbantes [...]; nec eo etiam quo quidam vetera novis, aut contra haec illis, sine ulla ratione certa praeferunt ».

76 Ibid.: «Constare enim vel huius lectione poterat, quod multa praeveniri ac caveri potuerint, quae alioqui qui in Ecclesiam ingenti innumerabilium animarum dispendio irrepserunt, quamvis ex eo ut et reliquis orthodoxis patribus quidam impietatum et seductionum prodigiossimarum patrocinia quaesiverint $»$.

77 Ibid.: « Oculos porro ad ministerii sacri institutionem undequaque intentos habet, ad quod ille non iniuria requirit doctos et exercitatos, atque cum primis eos, qui sint gregis exemplaria, factoque praestent quod doceant, et doceant quod vivant ».

78 Ibid.: «Iustitiam per fidem in Christum contingere sic opere toto docet, ut totus Christum sapiat. Depingit autem fidem non mortuam sed ornatam fructibus bonorum operum et efficacem, ut tamen fateamur interim, nos esse inutiles servos, exigitque non quaevis opera, quae rationis instinctu constituantur, verum ea tantumque quae a domino praecepta sunt, et ex scripturarum hauriuntur oraculis ».

79 Ibid.: «De redemptione nostra sic loquitur, ut ostendat nullum quantumvis sanctum eam peragere potuisse, cum deus mundam consummatamque hostiam pro summa iustitia sua exegerit, unde Christus homo factus mediatorque Dei et hominum constitutus, sanguinis sui interventu nos ex potestate diaboli, mortis ac peccati liberavit, propterque nostram iustitiam ut Paulus loquitur, resurrexit, nobis simul conresuscitatis collocatisque in coelibus ». 
temas ${ }^{80} \sin$ polemizar en ningún momento; destaca que Gregorio combatió a herejes ${ }^{81}$ y que habla de otras ciencias desde la filosofía, ${ }^{82}$ y alaba su capacidad para concitar lugares diversos de la Escritura y atener a ella sus explicaciones. ${ }^{83}$ Tiene el mismo tono para con sus obras al describirlas por separado, excepto por lo que se refiere al epistolario, que dice requiere un lector prudente (sin llegar a explicitar la razón),$^{84} \mathrm{y}$, sobre todo, los Dialogi, de los que no hará sino admitir que duda de la autoría de Gregorio, en virtud del estilo, el espíritu, la gravedad y el cuidado de la obra: «De Dialogis in quibus patrum Italiae miracula recenset, vix habeo quid pronunciem, nisi quod Gregorii esse dubitem, adeo et genio, et serie orationis, gravitate et industria distant a reliquis eius scriptis ómnibus ».

Puede decirse, pues, que la lectura de Coccius diverge un tanto de la de los padres de la Reforma. Si éstos vieron que Gregorio introdujo elementos humanos en su pensamiento y los divulgó, corrompiendo así la pureza originaria de la religión cristiana, e incluso parecieron ver los Dialogi como la cumbre de esa intrusión de lo humano, Coccius, en su aproximación filológica al autor, va más allá y ve en el exceso de los Dialogi una contradicción con sus restantes escritos: para él, en efecto, parece resultar contradictorio que un teólogo que tan fielmente se somete a las Escrituras pueda escribir una obra de santos y milagros en un estilo bajo que contradice el de sus obras exegéticas. Hay que decir, eso sí, que Coccius tiene una visión mucho más favorable que otros protestantes de la exégesis de Gregorio, ya que cuando aquéllos consideraron que el alegorismo del autor implicaba alejarse de la verdadera comprensión de la Escritura, Coccius ni siquiera describe la interpretación alegórica como la claramente dominante y representantiva de Gregorio, antes bien, sólo alude al método interpretativo de Gregorio al hablar de los Moralia, diciendo que en esta obra el autor ofrece distintos sentidos de interpretación, de modo que el lector pueda tomar el que le sea más apropiado ${ }^{85} \mathrm{Ni}$ que decir tiene que realmente es el sentido alegórico el

so Ibid.: « Neque enim tractat quaestiones quales in nonnullis scolasticorum reperias, frivolas et aniles, sed pias atque utiles geniumque habentes... ». Y cita algunos pasajes sobre el sentido de los sueños o la ira de Dios, que explica « non rationibus e carnis sapientia, sed scripturae authoritate depromptis».

81 Ibid.: «Haereticos praeterea refutat, Pelagium, Manichaeum, Celestinum, acalios, errores ipsorum detegens ».

82 Ibid.: « Naturalia themata, ex quae ab humana sapientia sunt petita, ex Philosophia discutit ».

83 Ibid.: «Conciliat locos scripturae in speciem pugnantes mira industria... Locis communibus inhaeret multis, ut est Fides, Charitas, Patientia, quos sacrarum literarum authoritatibus digerit, ac illustrat exemplis. Ac ut summatim dicam, non solum susceptos libros exponit, verum et totius scripturae considerationem depromit ».

$84 \quad$ Ibid.: « Epistolarum liber magnus sane, et qui multa eaque varia continet, sed requirit lectorem circumspectum ac prudentem, et qui non careat iudicio ».

85 Ibid.: «Adhibuit autem in eo libro singularem quandam diligentiam, ut non tantum genuinam sententiam secundum litteram, verum et allegorias, interpretatione nominum Hebraicorum, 
predominante, y el casi exclusivo a partir del libro IV. Esta visión contrasta con Lutero hablando de los delirios de Gregorio o con la apreciación de Zwinglio de que los Moralia eran uno de los exponentes de la errada interpretación alegórica de la Escritura. Coccius, en definitiva, presenta una imagen claramente más benévola del Gregorio exegéta que sus predecesores, en detrimento principalmente de sus Dialogi.

\section{El Catologus testium veritatis y las Centurias de Magdeburgo}

No fue hasta la década de 1550 que la difusión de las ideas reformadas vino acompañada de una proyección propiamente historiográfica. En 1556, el teólogo luterano Matías Flacio Ilírico publica en Basilea una obra con el propósito de reunir textos de la tradición cristiana que acrediten la preservación de la verdad revelada en el Evangelio contra las doctrinas de los papas: el Catalogus testium veritatis. La obra fue revisada y vuelta a publicar en 1562 en Estrasburgo, edición que usaré aquí. ${ }^{86}$ Gregorio figura entre los testigos de la verdad, y de él se dice que "vehementer pugnavit contra primatum papae ", mencionando las epístolas sobre el caso de Juan de Constantinopla y citando algunos fragmentos. También cita los Dialogi en atención a la doctrina del Purgatorio, apuntando que, contra lo defendido por los católicos, para Gregorio se trata de un fuego que quema sólo los pecados más leves. También dice que Gregorio fue el primer obispo de Roma en emplear el título de "servus servorum Dei », el cual sus sucesores, ávidos de poder, habrían interpretado falsamente como título del primado universal.

Hasta aquí, es evidente la coincidencia con Lutero en lo que respecta al uso de Gregorio en la polémica contra el papado: el interés de la obra, en este sentido, está en que proporciona una visión sistemática del asunto. Hay que apuntar, eso sí, que Flacio Ilírico recupera un episodio narrado en las biografías de Gregorio según el cual el pueblo romano habría quemado sus obras tras morir, y considera

naturam rerum figurarum ostendat. Nec una declaratione, quamlibet scripturae consentanea, contentus, plerumque et diversas adducit, relinquens lectori iudicium ut potiorem eligat ».

86 Matthia Flacius Illyricus, Catalogus testium veritatis, qui ante nostram aetatem Pontifici Romano, eiusque erroribus reclamarunt: iamque denuo longe quam antea, et emendatior et auctior editus, Johannes Oporinus, Argentinae 1562, p. 47-51. Hubo otra reedición publicada en Francia dos tomos en 1597, mucho más ampliada, donde, por lo que respecta a nuestro autor, se recogen citas de Gregorio que, tomadas fuera de contexto, parecen concordar con las doctrinas teológicas protestantes. Por alguna de estas citas podría deducirse, por ejemplo, que Gregorio defendió la justificación exclusivamente por la fe, cosa que ninguno de los autores de la época que aquí estamos viendo le atribuyó. Es evidente el todavía mayor tono de polémica antipapal de esta reedición póstuma. La obra, de todos modos, queda fuera de la cronología a que este artículo se circunscribe: Catalogus testium veritatis, qui ante nostram aetatem Pontifici Romano atque Papismi erroribus reclmarunt. Postrema hac editione emendatior et duplo auctior redditus, ordine dispositus, in libros XX tributus, atque ita renovatus, ut plane novus videri possit, t. I, Ex typographia Antonii Candidi, Lugduni 1597, p. 503-519. 
que tal hecho se debió a una respuesta contra la religión deturpada y los muchos elementos fabulosos ( multa fabulosa ») de sus escritos ${ }^{87}$ Es bastante verosímil que en este último aspecto el autor tuviera en mente los relatos de santos y milagros que en realidad se hallan sólo en los Dialogi. El mismo término, fabulosa, será el empleado por las Centurias de Magdeburgo precisamente para definir el contenido de esta obra. No obstante, Flacio Ilírico entiende también, en la línea de Lutero, que la religiosidad de Gregorio ya no sería pura, por lo que los Dialogi, pese a su impiedad, no serían la única obra controvertida del autor.

El propio Flacio Ilírico coordinó la redacción de un proyecto historiográfico más amplio que pretendía dar lugar a una historia de la Iglesia desprendida de los errores católicos, de lo cual el Catalogus testium veritatis sería, según el autor declara en el prólogo, sólo una mirada preliminar. El resultado fue la Ecclesiastica historia o Centurias de Magdeburgo, como la vengo llamando aquí, cuyos tomos se publicaron en Basilea entre 1559 y 1574. Cada tomo está dedicado a un siglo de la historia de la Iglesia, de ahí el nombre de Centurias. El tomo VI, donde se realiza el principal examen de Gregorio y sus obras, se publicó en $1562 .{ }^{88}$ El trabajo de búsqueda e interpretación de las fuentes incluyó a más personas que Flacio Ilírico, por lo que las conclusiones no son siempre idénticas a las del Catalogus.

El realizado por este tomo de las Centurias es el primer estudio sistemático de la persona y la producción de Gregorio desde una óptica protestante. Entre sus fuentes, además de las propias obras del autor, pueden reconocerse la Vita de Juan Diácono (a la que se cita en varias ocasiones), las Expositiones in Vetus Testamentum de Isidoro de Sevilla ${ }^{89}$ y las biografías publicadas en los opera omnia de Coccius, ${ }^{90}$ que quizá fueran la edición empleada por los centuriadores. En el análisis de la vida de Gregorio se localizan ya elementos que acreditarían el carácter supersticioso del autor: el episodio tomado como ejemplo pertenece a la Vita de Juan Diácono, donde se narra que Gregorio condenó a un monje a muerte por ocultar tres monedas de oro contra lo prescrito en su regla monástica, ello a

87 Matthia Flacius Illyricus, Catalogus testium veritatis, p. 51: « Post eius mortem voluit populus et clerus Romanus eius libros exurere. Credo propterea, quia viderunt nimis multa fabulosa inserta esse, et religionem non parum per eum contaminatam esse ».

88 Sexta Centuria Ecclesiasticae Historiae, continens descriptionem amplissimarum rerum in regno Christi, quae Sexto post eius nativitatem seculo acciderunt: cum Imperium Romanum gubernarent, Anastasius, Iustinus senior, Iustinianus, Iustinus iunior, Tiberius et Mauricius: et Doctores in Ecclesia praecipui eminerent, Fulgentius, Ferrandus, Avitus Alcimus, Maxentius, Hosmida, Boetius, Evodius, Iustus Origelitanus, Fortunatus, Cassiodoros, Gregorius Magnus, Olympiodorus, Andreas Hierosolymitanus, Gildas, Rusticus, et alii quidam: eodem ordine, diligentia et fide, quo superiores Centuriae, ex vetustis et probatis historicis, patribus et aliis scriptoribus, Per Ioannem Oporinum, Basileae 1562.

89 Ibid., col. 680: « Isidorus tamen Hispalensis urbis episcopus, in expositione Geneseos, Gregorium insigniter eloquentem pronunciat $»$.

90 Ibid, col. 678: « ...ut Iohannes Stella, Diaconus, Platina et alii scriptores testantur ». Se copia asimismo el epitafio de Gregorio que editó Coccius (ibid., col. 687-688). 
pesar del arrepentimiento del monje. ${ }^{91}$ Aunque se alaban su santidad y su doctrina, se advierte de que ésta se halla corrompida en algunos aspectos, y añade específicamente que escribió los Dialogi para que el vulgo aceptara con mayor facilidad sus propias tradiciones y ceremonias humanas. Del contenido de la obra se dice expresamente que "pleraque aut fabulosa sunt, aut manifeste impia, nec obscure falsam speciem religionis prae se ferunt $» .^{92}$

Los centuriadores llevan a cabo una extensa valoración de la doctrina gregoriana, citando numerosos fragmentos de sus obras. Lo que tiene que ver con la cristología, la doctrina trinitaria y otros dogmas de fe son ortodoxos. Las críticas se dirigen hacia la penitencia, que se considera contaminada por la idea de que los pecados pueden borrarse no exclusivamente por la gracia divina, sino mediante la acción misma de la penitencia (« ex opere operato »); también, en el mismo sentido, hacia el excesivo valor concedido a las obras frente a la gracia, y a la defensa del libre albedrío, si bien se apunta que ello viene dado por influjo de la situación de las creencias de su tiempo. Además, se añade que Gregorio justifica el culto a las estatuas y el celibato sacerdotal, y se recupera la idea de que el sentido del título de « servus servorum Dei » por él empleado fue deturpado por los papas siguientes. Hay asimismo un apartado en que se habla de su lucha contra los herejes y sus innovaciones litúrgicas ${ }^{93}$ Respecto al episodio de la quema de sus libros tras su muerte, en este caso se atribuye a una mentira de sus émulos, y no a un acto de respuesta popular contra sus doctrinas. ${ }^{94}$

En líneas generales, pues, se trata de una visión de Gregorio muy cercana a la que parecía tener Lutero. Llama la atención, eso sí, que, al igual que hizo Coccius, los centuriadores no mencionen el método de interpretación alegórico de Gregorio a las Escrituras, que los humanistas y los primeros padres de la Reforma claramente despreciaron. El interés predominante aquí es el de hallar y señalar lo que hay de correcto o de incorrecto en Gregorio en virtud de unos principios dogmáticos ya establecidos. En su aproximación a Gregorio buscan la confirmación de una doctrina, o, por el contrario, los errores que van contra ella; no leen a Gregorio críticamente en busca de la correcta interpretación de la

91 Ibid., col. 677: «Fratribus quoque regulam tradidit, ut omnes communiter viverent, nec quisquam propria possideret: eamque adeo superstitio se observavit, ut aliquando Iustum monachum, cuius ope medica antea saepe fuerat adiutus, cum contra regulam tres aureos occultasset, in mortis agone (quod tamen magnam Magni illius Gregorii pietatem parum commendat) sine consolatione relinqueret: vivum diabolo, quantumvis poenitentem, et peccatum illud anxie deplorantem, traderet $»$.

92 Ibid., col. 678.

93 Para todo ello, cf. Ibid., col. 679-687.

94 Ibid., col. 688: «Post mortem eius ingrente fame, aemuli prodigium et dilapidatorem omnis thesauri eum dixerunt, et parum abfuisset quin libros eius omnes combussissent: nisi se Petrus Diaconus, qui afferebat se Spiritum S. in specie columbae super Gregorii caput vidisse, interposuisset ». 
verdad revelada. La diferencia puede parecer sutil, pero parte de un dogmatismo que acentúa la visión de Gregorio como auctoritas contra el catolicismo. Dicha tendencia, consecuencia de la consolidación de los dogmas y supuestos sobre los que se asentaba la irreconciliable disputa entre católicos y protestantes, no hará sino intensificarse en las décadas siguientes.

\section{Conclusiones y visión posterior de Gregorio}

Según hemos visto aquí, las líneas generales de la percepción protestante de Gregorio en el primer medio siglo de la Reforma consisten en ver en él a un hombre santo, cuya doctrina conserva puras determinadas verdades de la revelación evangélica que los papas habrían deturpado, pero que también fue un hombre que vivió en un tiempo de corrupción, y que él mismo, como hombre, cedió a la superstición y le dio autoridad en la Iglesia: así ocurre con la doctrina del purgatorio, el culto a los santos, las misas privadas y otros. Si bien su influencia en la configuración de la doctrina protestante parece haber sido escasa, las cartas de Gregorio concernientes a la disputa con Juan de Constantinopla fueron un argumento recurrente desde las primeras polémicas de Lutero para sostener que el primado universal no era una institución de derecho divino. Por lo demás, entre los primeros padres de la Reforma, el alegorismo de Gregorio les valió el mismo desprecio que había tenido Erasmo; aun así, es perceptible que con más o menos frecuencia citan a Gregorio cuando su interpretación les parece válida: tal es la postura humanista propia de estas décadas. Más allá de esto, podemos hallar diferencias sutiles en la aproximación a Gregorio, destacando la inspiración que el espíritu pastoral del papa ejerció sobre Calvino. Por lo demás, los Dialogi emergen aparentemente en Lutero como la obra más representativa del carácter supersticioso de Gregorio, si bien dicha superstición es bien perceptible en otras ideas defendidas por él.

A partir de 1550, leemos valoraciones de Gregorio procedentes de quienes lo leyeron desde la perspectiva de unos supuestos, ideas y dogmas ya configurados, $\mathrm{y}$ en un contexto de polémica contra el catolicismo donde eran irreales las perspectivas de reconciliación. A partir de este momento podemos decir que la recepción de Gregorio en ámbito protestante entra en una fase diversa. Frente a la aproximación de espíritu humanista de Lutero, Zwinglio o Calvino, eruditos como Coccius o los centuriadores de Magdeburgo leen a Gregorio buscando sistematizar lo que hay de correcto o de incorrecto. Si bien Coccius no tuvo una motivación polémica, lo cierto es que leyó a Gregorio buscando también una síntesis de lo aprovechable de su doctrina. En su caso, además, su aproximación filológica a Gregorio le permitió hallar diferencias de estilo y " gravedad » entre los Dialogi y las obras exegéticas, a las que valoraba especialmente, sospechando por ello que los Dialogi podrían no ser una obra del papa. 
Esta nueva postura respecto a Gregorio será la que hereden los eruditos posteriores, que protagonizaron las polémicas más agudas sobre la autoría de los Dialogi. La evolución de la concepción de Gregorio dependerá entonces de los prejuicios o las de inclinaciones más o menos espurias de los estudiosos. Es digno de nota el que Robert Cooke vea contradicciones dogmáticas entre los Dialogi y el resto de obras de Gregorio donde Coccius había visto sólo una inapropiada diferencia de gravitas. ${ }^{95}$ Pero esta etapa de la historia es ya mejor conocida.

95 Obsérvese que Cave apunta que aquel extremo aún no había sido probado: « Litem his Dialogis intentant Reformatorum haud pauci. Strenue reclamantibus Romanae Ecclesiae Scriptoribus. Varia utrinque proferuntur argumenta... Tertio, reperiuntur in his Dialogis, quae doctrinae Gregorianae in operibus eius indubitatis traditae liquido adversantur, quorum omnium non unum exemplum, profert Rob. Cocus Nostras, Censur. script. vec. p. 209 » (Guilielmus CAve, Scriptorum ecclesiasticorum Historia Literaria, p. 431). 